Burns, J. J., and Conney, A. H. (1965). Proceedings of the Royal Society
of Medicine, 58, 955. Evans, D. A. P. (1968). Annals of the New York Academy of Science, $151,723$.

Freyschuss, U., Sjöqvist, F., Tuck, D., and Assberg, M. (1969). Pharmacologica Clinica. In press.

Hammer, W. M., and Brodie, B. B. (1967). Fournal of Pharmacology and Experimental Therapeutics, 157, 503.

Hammer, W., Ideström, C.-M., and Sjöqvist, F. (1967). In Antidepressant Drugs, edited by S. Garattini and M. N. G. Dukes, p. 301. Amsterdam, Excerpta Medica

Hammer, W., and Sjöqvist, F. (1967). Life Sciences, 6, 1895.

Herrmann, B. (1963). Helvetica Physiologica et Pharmacologica Acta, 21,402 .

Kolmodin, B., Azarnoff, D. L., and Sjöqvist, F. (1969). Clinical Pharmacology and Therapeutics, $10,638$.

Levi, A. J., Sherlock, S., and Walker, D. (1968). Lancet, 1, 1275.

McMahon, R. E., Marshall, F. J., Culp, H. W., and Miller, W. M.

(1963). Biochemical Pharmacology, 12, 1207.
Sjöqvist, F., Hammer, W., Borgå, O., and Azarnoff, D. L. (1969). In Collegium Internationale Neuro-psychopharmacologicum: The Present Status of Psychotropic Drugs, edited by A. Cerletti and F. J. Bové, p. 128. Amsterdam, Excerpta Medica.

Sjöqvist, F., et al. (1968). In Toxicity and Side-effects of Psychotropic Drugs, edited by S. B. de C. Baker, J. R. Boissier, and W. Koll, p. 246. Amsterdam, Excerpta Medica.

Snedecor, G. W., and Cochran, W. G. (1967). Statistical Methods, 6th ed., p. 285. Ames, The Iowa State University Press.

van Rossum, J. M. (1968). Fournal of Pharmaceutical Sciences, 57, 2162. van Rossum, J. M., and Tomey, A. H. M. (1968). Fournal of Pharmacy and Pharmacology, 20, 390

Vesell, E. S., and Page, J. G. (1968a). Science, 159, 1479.

Vesell, E. S., and Page, J. G. (1968b). fournal of Clinical Investigation, $47,2657$.

Vesell, E. S., and Page, J. G. (1968c). Science, 161, 72.

Yates, C. M., Todrick, A., and Tait, A. C. (1963). Fournal of Pharmacy and Pharmacology, 15, 432.

\title{
Human Babesiosis in Ireland: Further Observations and the Medical Significance of this Infection
} \author{
ital

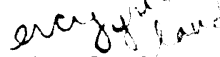 \\ P. C. C. GARNHAM,* C.M.G., M.D., D.sC., F.R.S. ; JOSEPH DONNELLY, † B.SC. \\ HARRY HOOGSTRAAL, $\ddagger$ M.S., PH.D., F.R.E.S. ; C. COTTON KENNEDY,§ D.M., F.C.PATH. \\ GERALD A. WALTON, $\|$ M.B., M.SC., F.R.E.S.
}

[With Colour Plate]

British Medical fournal, 1969, 4, 768-770

\begin{abstract}
Summary : Three splenectomized persons in Yugoslavia, $\checkmark$ California, and Ireland have been reported to be infected by three different Babesia species; two cases were fatal. In a study of the site where the fatal infection was contracted in Ireland, blood samples from 36 persons who had recently been bitten by ticks were inoculated into two splenectomized calves; no response to Babesia divergens was detected. Field-collected Ixodes ricinus ticks inoculated into another splenectomized calf resulted in fever and recovery of the agent of tick-borne fever (Cytoecetes phagocytophilia). This attempt to determine the presence of latent infection in human beings with intact spleens should be repeated on a larger scale in areas with a demonstrably high incidence of Babesia in ticks and animals. Few places in the world are free of piroplasms; their presence may present a hazard to splenectomized persons or to those whose splenic function is deficient.
\end{abstract}

\section{Introduction}

Three human cases of babesiosis have now been reported in the literature. Each occurred in a person who had undergone splenectomy some time previously, and was severe or fatal. Human beings with an intact spleen are apparently insusceptible to this cosmopolitan protozoal infection of the lower vertebrates.

The first human case was reported from Yugoslavia (Skrabalo and Deanovic, 1957). A farmer living on the outskirts of Zagreb had suffered internal injuries in a car accident 11 years

* Professor Emeritus, Imperial College of Science, Ascot, Berks.

† Senior Research Officer II, Central Veterinary Laboratory, New Haw, Weybridge, Surrey.

₹ From Research Project MF12.524.008-3010, Bureau of Medicine and Surgery, Department of the Navy, Washington, D.C. The opinions and assertions contained herein are the private ones of the author
and are not to be construed as official or as reflecting the views of the Department of the Navy or of the naval service at large. earlier and his spleen had been removed. He remained well until June 1956, when he was admitted to hospital very ill with fever, anaemia, jaundice, and haemoglobinuria. His blood contained numerous intraerythrocytic "rings" (Colour Plate, Fig. 1) which were identified as Plasmodium falciparum (Colour Plate, Fig. 2), and the condition was thought to be blackwater fever. The patient died eight days later. The rather unusual characters of the case raised some suspicion about the correctness of the diagnosis, and the blood films were sent for confirmation to Drs. N. H. Swellengrebel, R. Geigy, and E. Mudritz, and to one of us (P.C.C. G.). Each replied that the infection was babesial, not malarial. It seemed possible that the slides had been muddled with veterinary ones, but corpuscle measurements quickly confirmed that the cells were of human and not bovine dimensions. Epidemiological inquiries showed that the farm where the man lived was infested by ticks (Dermacentor silvarum and Ixodes ricinus) and that the cattle he had tended were infected with Babesia bovis.

The second case occurred in California in 1966 in a man who had visited relatively isolated coastal areas near San Francisco during the months preceding illness. $\mathrm{He}$ was admitted to hospital with chills and fever, diagnosed as a case of malaria, placed on $250 \mathrm{mg}$. of chloroquine weekly for about 15 weeks, and recovered (Scholtens et al., 1968). Because of hereditary spherocytosis, a splenectomy had been performed on the patient in 1964, at which time he received 13 units of blood. The case was diagnosed as babesiosis (Babesia sp.) when "Maltese-cross"-type organisms, but no malarial parasites, were found on the blood slides. Animal inoculations with blood taken about 90 days after onset of illness demonstrated no organisms. Babesia antibodies in the patient's serum were found in both complement-fixation and tube latex-agglutination tests.

$\checkmark$ Consultant Clinical Pathologist, Belfast City Hospital, Belfast, Northern Ireland.

(I Department of Zoology, University College, Cork, Ireland.

S But see Fitzpatrick et al. (1969) regarding a newly described fourth instance of human babesiosis. 
P. C. C. GARNHAM ET $A L$.: HUMAN BABESIOSIS IN IRELAND

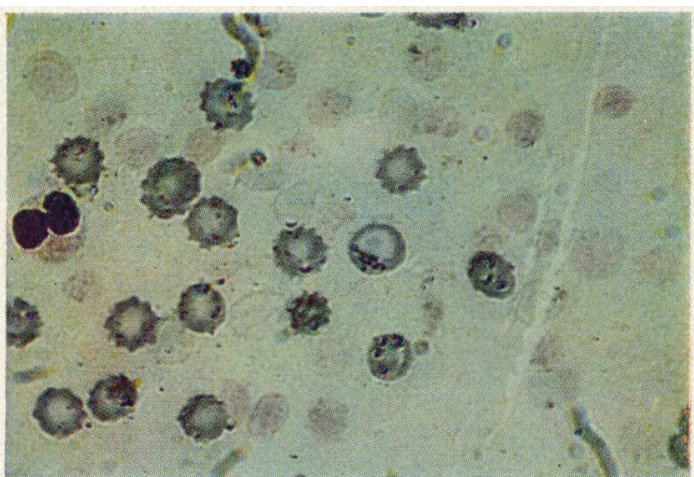

FIG. 1. - B. bovis from fatal infection in man. (x600.)

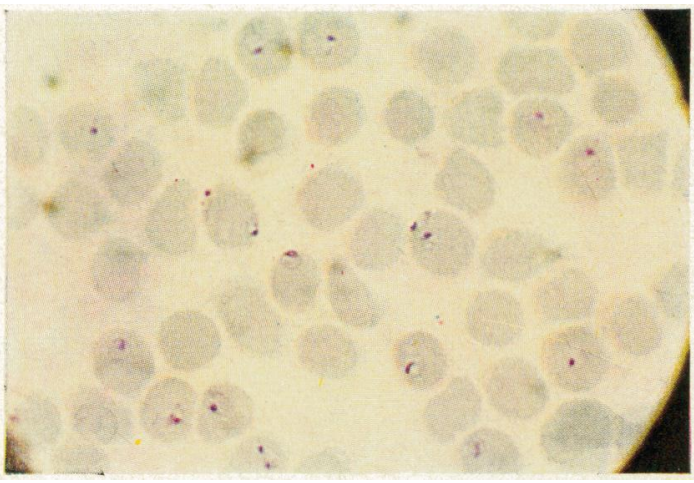

FIG. 2.-P. falciparum : typical infection in man. $(\times 1,000$.

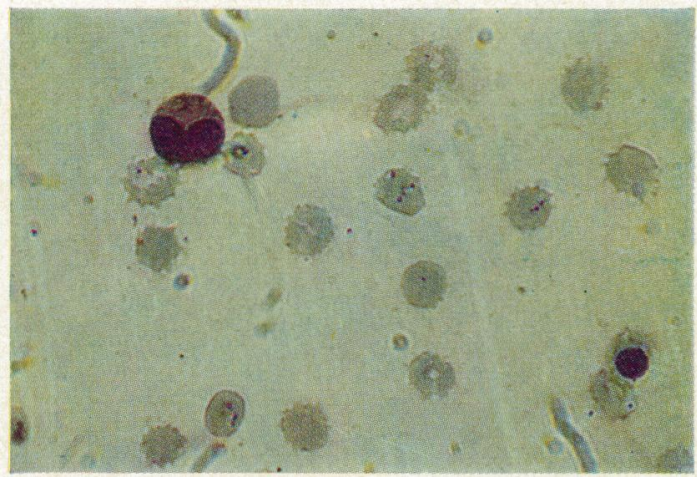

FIG. 3. $-B$. divergens $\underset{(\times 600 .)}{\text { frotal infection in man. }}$

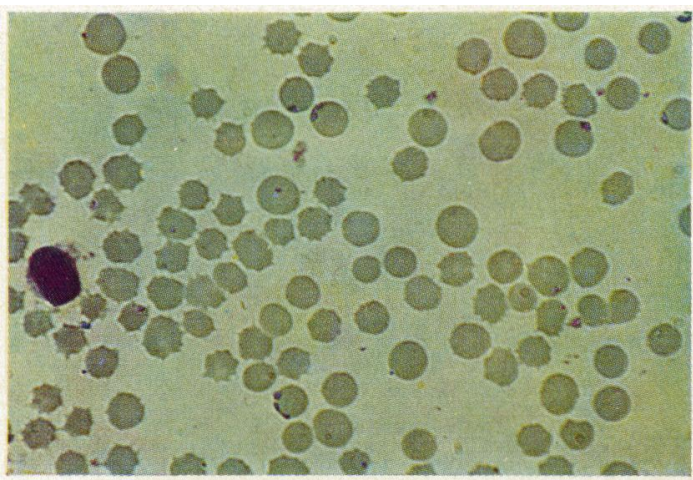

FIG. 4. $-B$. divergens frem cow. $(\times 600$.

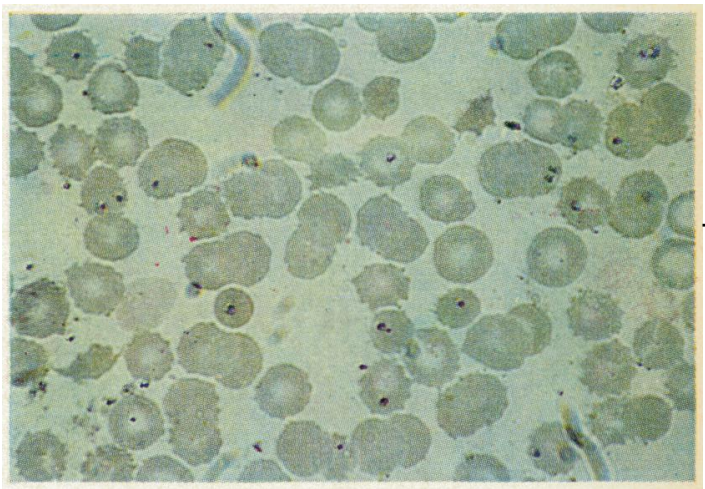

Fig. 5. - B. divergens from chimpanzee. $(\times 600$.

J. E. P. FITZPATRICK ET $A L$. : THIRD RECORDED CASE OF REDWATER IN MAN
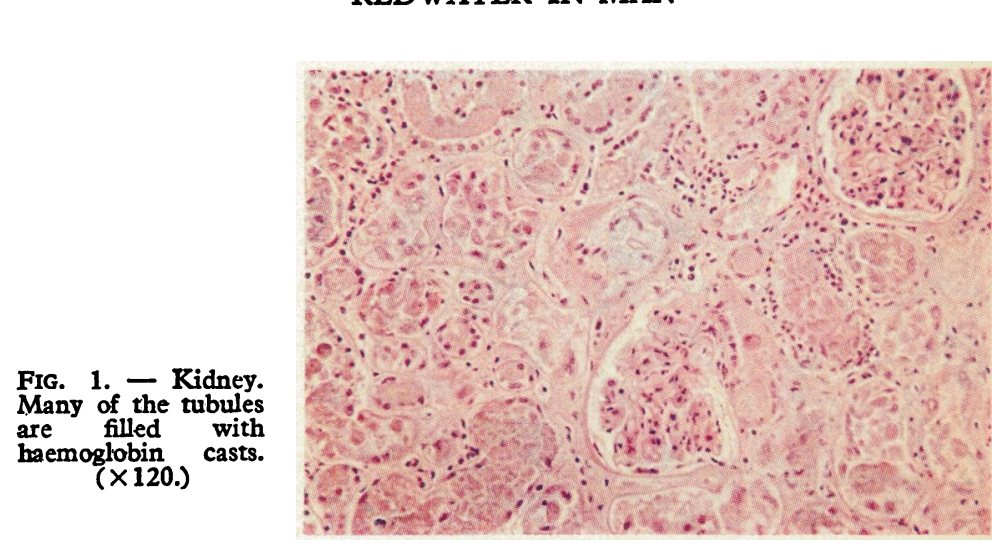

Frg. 2. - Liver. Excess of nucleated and excess of bile pioment both intracellularly and in bile canaliculi. ( $x$ 200.)

$$
\text { ? }
$$

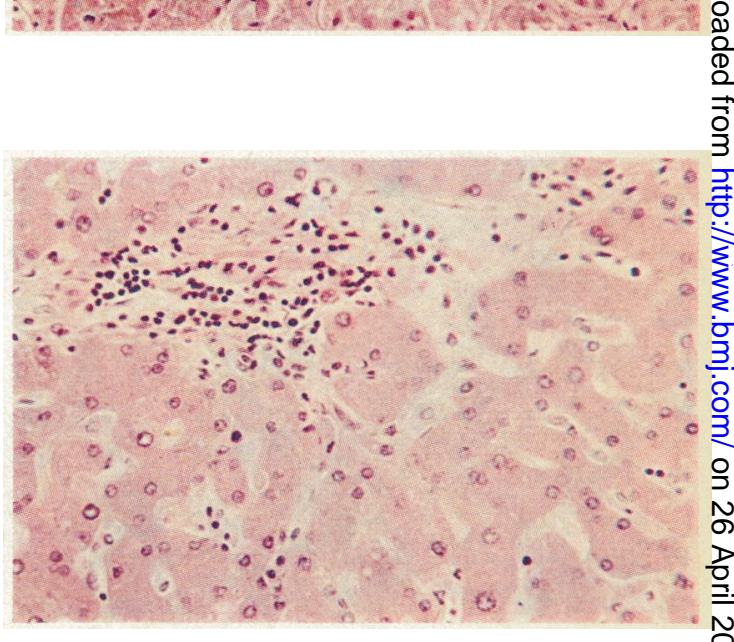


The third case was contracted in County Galway, Ireland, in August 1967 (Fitzpatrick et al., 1968). A deep-sea fisherman went with his family on holiday from Northern Ireland and stayed in a caravan from 15 to 19 August on the shores of Lough Corrib. On returning home he became very ill with fever, jaundice, and anaemia. Malaria-like "rings" (Colour Plate, Fig. 3) were found shortly before death in his blood. His condition rapidly worsened and he died within a week of becoming ill. The clinicopathological details of the case are presented by Fitzpatrick et al. (1969). Blood films were sent for confirmation of the diagnosis to the Malaria Reference Centre, Horton, where Mr. P. G. Shute was suspicious of the identity of the parasites and showed them to one of us (P.C.C. G.), who identified the infection as B. divergens. Subsequent inquiries by Fitzpatrick et al. (1968) revealed that four months earlier the man had undergone a difficult gastroenterostomy and vagotomy, as well as splenectomy and blood transfusion (the transfusions were at first thought to have been the origin of the "malaria"). The investigators later concluded that the patient had presumably contracted the disease from bites of infected ticks during the holiday at Lough Corrib.

Piroplasms apparently cause no disease in man with a spleen. These three cases were all in people who had had their spleens removed and had subsequently been exposed to tick bite where piroplasmosis existed in the animal population. It seemed to be of interest to determine whether normal people living in such areas were infected and whether latest infections might occur. We accordingly planned a small investigation in Galway. Briefly, our intention was to procure blood samples from people who had been exposed to infective tick bites, and to inoculate this material into splenectomized calves for evidence of infection. At the same time we wished to determine the prevalence of Babesia-infected ticks in this locality. The work is reported here in the hope that further research will be made on this interesting subject.

\section{Investigations and Results}

Exactly a year after the Irishman had stayed near Lough Corrib, we went to the precise locality, directed there by the regional medical officer, Dr. McConn. We hoped to find a sufficient number of rural workers in this area to test for evidence of infection. Within a mile $(1.6 \mathrm{~km}$.) of the lake we were held up by a large concourse of cars and saw a military assembly in the adjoining field. It was the Irish Army participating in the production of the M.G.M. film "Alfred the Great." The soldiers had spent much time during the previous fortnight in the fields, and were inevitably often bitten by ticks. Our experiment had been done for us. We lost no time in asking the commanding officer to provide volunteers for blood samples ; he at once agreed, gave $10 \mathrm{ml}$. of his own blood, and produced 36 soldiers who did likewise.

The blood was heparinized in bulk in the travelling laboratory of one of us (C.C.K.) which was parked on the site, and the material was placed in ampoules in a large vacuum flask containing ice. This container was taken to Shannon Airport and flown to London, where it was picked up by one of us (J.D.). Ice was still present in the flask at the Central Veterinary Laboratories, Weybridge. The samples were mixed, warmed to $37^{\circ} \mathrm{C}$., and $120 \mathrm{ml}$. was inoculated intravenously and subcutaneously into each of two splenectomized calves, about 10 weeks old. The blood of inoculated animals was examined daily for 18 days, but no parasites were detected, no fever occurred, and the calves responded normally to challenge with $B$. divergens five weeks later. The normal response confirmed that the animals had not acquired an occult infection from the original inoculation. Three recently splenectomized mice and two splenectomized rats were also available at Weybridge, and the opportunity was taken to inoculate the human blood sample into the animals also. No Babesia was detectable in blood smears during the subsequent two weeks following inoculation.

The area in which the Irishman and his family stayed was investigated qualitatively for the presence of ticks. The caravan they occupied in 1967 was located near a footpath bordered on one side by a high thorn and nut thicket ( 7 metres wide) and on the other side by the lake foreshore near Moycullen, Co. Galway. Behind the lakeside thicket are small hilly stonewall-enclosed cattle pastures with scattered bracken (Pteridium), briars (Rubus and Rosa), and small blackthorn bushes (Prunus spinosa). I. ricinus ticks were present and active throughout the pastures. With white turkish towelling blanket drags (Macleod method) 3,000 larvae were collected from pasture vegetation. More than 30 larvae were taken on blanket drags on the dry lakeshore. With white turkish towelling flags (75 by $25 \mathrm{~cm}$.) on short handles (N.A.M.R.U.-3 method) some 30 nymphs and two unfed females were obtained from low pasture scrub and bracken, and 17 nymphs were removed from the thicket bondering the footpath in the immediate area of the caravan.

Cattle were numerous, and, though the blood of several animals appeared to be negative on the present occasion, the veterinary officer of the district (Mr. J. A. Fagan) informed us that cases of redwater fever, caused by $B$. divergens, were not uncommon in these herds. One of us $(H . H$.$) took this collec-$ tion of 1 . ricinus (8 adults, 32 nymphs, and about 3,000 larvae, all unfed) to Weybridge, where they were put on to the left ear of a third splenectomized calf. Another 71 uninfected adult I. ricinus were placed on the right ear of this animal in an unsuccessful attempt to pick up any infection transmitted by the field-collected ticks, most of which fed and detached from the host eight days later. The temperature of the calf was read daily and its blood was examined for parasites. None was found, but the animal developed a high fever from day 8 to 13 . The agent of tick-borne fever (Cytoecetes phagocytophila) was found in the leucocytes of the blood. Two months later this animal was challenged with $B$. divergens (Colour Plate, Fig. 4) and a low parasitaemia occurred.

It might be noted that one of us (C. C. K.), who had participated in the collection of ticks from 8 to 10 August, became slightly ill on 13 August with tiredness, headache, and anorexia but no pyrexia; a blood film was taken but no parasites were found.

\section{Discussion}

Inapparent or latent infections are a common feature in many microbiological infections of man (Nicolle, 1961), and can be detected only by employing special techniques. Thus Trypanosoma rangeli is so rare in the blood that the organism is usually demonstrated only after blood culture or by senodiagnosis. Likewise, occult infections of spirochaetes in monkeys become visible only by splenectomizing the animals, and human malaria parasites such as $P$. vivax or $P$. malariae multiply in the blood of chimpanzees only after splenectomy.

In such instances the intact animal is partially insusceptible to the organism and few parasites circulate in the blood, probably for a limited period. Piroplasm infections of bovine origin possibly behave similarly in man, and at a certain stage should be detectable by refined techniques, particularly by inoculation into splenectomized calves.

Several factors may have contributed to the inability to find latent infections in normal people in the Irish enzootic area. The incidence of babesiosis might be low in this actual locality, though relatively high elsewhere in the region. The basic challenge is certainly low-that is, only a very small number of ticks are infected. Cattle are continuously subject to this low challenge-that is, for most of the daylight hours for seven to eight months of the year. The soldiers were exposed for only a limited period. There is also the possibility that the disease is transmitted only during the final stages of engorge- 
ment of the tick. Cattle allow ticks to complete feeding, but men would tend to remove them as soon as they were noticed. We had no exact data on when the tick-transmitted infection might be expected to appear in human blood. The incubation period in cattle of 8 to 14 days (Joyner et al., 1963) coincides with the period of exposure of the soldiers in the tick-infested fields. The duration of parasitaemia (even if it occurs at all) in unsplenectomized man is unknown, and maximum intensity may occur later than the fortnight period during which these soldiers were exposed. Other factors inhibiting infection in these soldiers may have been present in the environment, such as nutrition, fluoride excess in the water, concomitant infections, etc. Lastly, the experimental techniques may not have been ideal, as the blood was not inoculated until 24 hours after having been taken, though such a delay does not eliminate the infectivity of cattle blood.

Man, particularly agricultural workers and people who spend much time in rural areas, undoubtedly comes into contact with Babesia-infected ticks quite frequently. Three species of piroplasms have been the cause of the three cases reported from human beings. Few places in the world are free of piroplasms ; their presence presents a hazard to numerous people who are splenectomized and an unknown number whose splenic function is deficient.

A follow-up of 1,118 patients who had been splenectomized in England (Lowdon et al., 1966) showed that 417 died in the five years after the operation, and all but six deaths were ascribed to a definite cause. None of the fatalities appeared to have been due to piroplasmosis, but this condition could have been overlooked or misdiagnosed. The great virulence of these infections for man without a spleen and the difficulty of diagnosis make it desirable that the danger should be appreciated. Antimalaria drugs were found to be ineffective in the first human case. A veterinary preparation such as amicarbalide (Diampron) at a dose of $10 \mathrm{mg} . / \mathrm{kg}$. might be considered for use in future cases.
Chimpanzees provide a good experimental model in that these animals suffer from severe infections of $B$. divergens (Colour Plate, Fig. 5) when deprived of their spleens (Garnham and Bray, 1959). The date of spleen removal has no relevance to the intensity of the infection, and it may be assumed that its anti-piroplasmal function cannot be taken over by other tissues. It would be interesting to determine the range of species that can infect chimpanzees and man. Chimpanzees have been shown to be insusceptible to Theileria parva, but at least 30 species of Babesia (sensu latu) remain to be tested.

This work should be extended in suitable enzootic regions, and N.A.M.R.U.-3 is presently undertaking research on similar lines to those described in this paper in the Nile Delta region of Lower Egypt.

We are grateful to our Irish colleagues for their co-operation in this wosk and particularly have to thank Dr. C. F. McConn, regional medical officer, and Mr. J. A. Fagan, veterinary officer, who located the precise site of the infection, and who helped us in many ways. We have much pleasure also in acknowledging the kindness of Drs. Kendall and Joyner, of the Central Veterinary Laboratory, for providing the laboratory facilities for this work and the latter for splenectomizing the calves.

\section{REFERENCES}

Fitzpatrick, J. E. P., Kennedy, C. C., McGeown, M. G., Oreopoulos, D. G., Robertson, J. H., and Soyannwo, M. A. O. (1968). Nature, 217,861 .

Fitzpatrick, J. E. P., et al. (1969). British Medical fournal, 4, 770.

Garnham, P. C. C., and Bray, R. S. (1959). Fournal of Protozoology, $6,352$.

Joyner, L. P., Davis, S. F. M., and Kendall, S. B. (1963). Experimental

Parasitology, 14, 367.
Lowdon, A. G. R., Stewart, R. H. M., and Walker, W. (1966). British Medical fournal, 1, 446

Nicolle, C. (1961). Destin des Maladies Infectieuses. Geneva, Alliance Culturelle du Livre.

Scholtens, R. G., Braff, E. H., Healy, G. R., and Gleason, N. (1968). American fournal of Tropical Medicine and Hygiene, 17, 810 .

Skrabalo, Z., and Deanovic, Z. (1957). Documenta de Medicina Geographica Tropica, 9, 11 .

\title{
Further Details of Third Recorded Case of Redwater (Babesiosis) in Man
}

\author{
J. E. P. FITZPATRICK,* M.B., M.C.PATH. ; C. COTTON KENNEDY, $\dagger$ D.M., F.C.PATH. \\ MARY G. MCGEOWN, $\ddagger$ M.D., M.R.C.P.ED., PH.D.; D. G. OREOPOULOS, $\S$ M.D. \\ J. H. ROBERTSON, $\|$ M.D., M.R.C.P.ED., M.C.PATH. ; M. A. SOYANNWO,g PH.D., M.R.C.P.I.
}

[With Colour Plate facing Page 768]

\section{British Medical Fournal, 1969, 4, 770-772}

The Fifth Plague, "Behold, the hand of the Lord is upon thy cattle which is in the field, upon the horses, upon the asses, upon the camels, upon the oxen, and upon the sheep: there shall be a very grievous murrain "** (Exodus, chap. 9, v. 3).

Summary : Clinical details and laboratory and post$S$ mortem findings of a human case of redwater (piroplasmosis or babesiosis) caused by Babesia divergens. This is the third proved case in man. All three patients had had splenectomies.

\section{Introduction}

The fulminating haemolytic illness which may result from malarial infection is well known. It is not widely appreciated, however, that a similar illness can be caused in man by infection

\footnotetext{
** "Murrain" in many parts of Ireland is synonymous with redwater in
} cattle, with another intra-erythrocytic protozoon, Piroplasma (Babesia), the cause of redwater disease in animals. There have been only two previous authenticated reports of human piroplasmosis, one from Jugoslavia (Skrabalo and Deanovic, 1957), the other from the United States (Braff and Condit, 1967). The present report is of a third patient who contracted the disease in Ireland. A preliminary account of the case has previously been published (Fitzpatrick et al., 1968).

* Senior Registrar, the Laboratories, Belfast City Hospital, Belfast BT9 7AD.

+ Consultant Clinical Pathologist, the Laboratories, Belfast City Hospital ¥ Consultant Nephrologist, Belfast City Hospital.

† Consultant Nephrologist, Beifast City Hesplogl. Belfast City Hospital

Former Registrar, Deparment of Nephrology, Belfast City Hospital

Consultant Clinical Pathologist, the Laboratories, Buthority, Departmen of Nephrology, Belfast City Hospital.

Requests for reprints to be sent to Dr. C. C. Kennedy, the Laboratories, Belfast City Hospital, Belfast BT9 $7 \mathrm{AD}$, N. Ireland. 